\title{
Phenotypic Characterization of 14 Colombian Families with Bartter and Gitelman's Syndromes
}

\author{
Lina María Serna Higuita ${ }^{1 *}$, Lina María Betancur Londoño ${ }^{2}$, Carlos Mauricio Medina Vásquez² Lorena Urbano $^{2}$, \\ Ana María Garcia ${ }^{1}$, Nicolas Pineda-Trujillo² and Juan José Vanegas Ruíz ${ }^{1,2}$
}

${ }_{1}^{1}$ Institute for Clinical Epidemiology und Applied Biometrics, Eberhard Karls University, Germany

${ }^{2}$ Department of Pediatrics, Universidad Pontificia Bolivariana, Colombia

${ }^{3}$ Gene Mapping group, Universidad de Antioquia, Colombia

Submission: June 16, 2017; Published: June 30, 2017

*Corresponding author: Lina Maria Serna Higuita, Institute for Clinical Epidemiology und Applied Biometrics, Eberhard Karls University, Germany, Email: lm.serna@hotmail.com

\begin{abstract}
Bartter and Gitelman's syndromes are hereditary disorders characterized by a remarkable reduction of salt transportation by the thick ascending limb of the Henle's loop. Consequently, patients suffering from Bartter syndrome present with renal salt wasting, low blood pressure, hypokalemic metabolic alkalosis and hipercalciuria and are at risk of developing renal stones. Recent progress in molecular genetics has contributed to classify the syndrome in different subtypes, depending on the channel involved. Very little is known on the phenotypic characterization of this disorder in Colombia-South America.
\end{abstract}

Aim: to determine the phenotypic characteristics of 18 patients from 14 families with Bartter and Gitelman's syndromes recruited in Medellin-Colombia.

Methods: retrospective study based on reviewing the clinical records of patients with clinical diagnosis of Bartter or Gitelman's syndrome, during 15 years.

Results: 18 patients. 8(47\%) patients presented with Gitelman's syndrome, 8(47\%) neonatal Bartter and 2(11.1\%) classic Bartter; the average current age was 12.8 years. The time between the first symptoms and the establishment of the diagnosis was: Gitelman's syndrome 3-196 months; 5-120 months for classic Bartter; and between 1-36 months for neonatal Bartter. Main symptoms in the patients with neonatal Bartter were vomit, polyuria, polydipsia, short stature, fever and paresthesias. Patients with Gitelman's syndrome mainly presented with muscle weakness, paresthesias, polyuria and polydipsia. Blood pressures in all of the patients were within normal limits. Nephrocalcinosis was observed in six patients (35.2\%). 100\% of the patients with the neonatal Bartter syndrome with potassium supplements; $87.5 \%$ are being treated with spironolactone; $62.5 \%$ take indomethacin; only one of the patients takes magnesium. $100 \%$ of the patients Gitelman's syndrome required potassium and magnesium; $25 \%$ take indomethacin; $62.5 \%$ take spironolactone. And only one patient received ECA inhibitors.

Discussion: This is the first Colombian study aiming at characterize the phenotypic features in a set of patients with Bartter and Gitelman's syndromes. Here we report the clinical and laboratory characteristics of 18 cases.

Keywords: Bartter's syndrome; Gitelman's syndrome; Polyhydramnios; Hydroelectrolytic disturbances; Hypokalemia; Nephrocalcinosis; Consanguinity; Recessive inheritance

\section{Introduction}

Bartter and Gitelman's syndromes are a group of hereditary tubulopathies with both a marked reduction on the urinary concentration and a decrease in the transport of the sodium chloride in the distal nephron; they are characterized by salt renal lost, hypokalemia [1,2] hyperreninemic hyperaldosteronism and juxtaglomerular hyperplasia [3,4]. It is a rare disease, its prevalence is approximately 1 in 50.000 inhabitants [5]; it has neither ethnic predilection nor gender differences.
Its inheritance pattern is medelian. So far, five subtypes of the syndromes have been identified. These subtypes differ on age of onset, symptoms, severity and electrolytes loss [6]. The Gitelman's syndrome is recognized from the Bartter's by the hypomagnesaemia and hypocalciuria seen in the former $[4,6]$.

Bartter syndrome type 1 is caused by mutations in the NKCC2 gene (chromosome 15q15-21) [7-9]. This gene encodes the $\mathrm{NaK} 2 \mathrm{Cl}$ channel, which is responsible for the chloride 
luminal resorption by means of the co-transport of potassium in the thick ascending Henle loop [10].

Bartter type 2 is caused by mutations in the KCNJ1 gene (chromosome 11q24-25) [11,12], which encode the ROMK channel. This channel is a potassium membrane transporter [13]; It's mutations may alter the potassium secretion in the Henle loop and in the collecting duct $[7,14]$. These two variants (type 1 and 2) called neonatal Bartter's syndrome are characterized by polyhydramnios (secondary to the neonatal polyuria) and premature delivery $[6,13]$. Affected neonates persist with polyuria and hypostenuria (low urine density), which is cause of hypokalemic metabolic alkalosis and hipercalciuria; this is a risk factor for developing early nephrocalcinosis and renal insufficiency $[4,5,7]$; besides, there is a high expression of prostaglandin E2 and renin [15], which explain fever, vomit and occasional diarrhea [8]. These two types of Bartter may also present with osteopenia and a marked growth delay $[8,13,16,17]$.

Measures of arterial gases and ions such as sodium, potassium, calcium and magnesium in both blood and urine are used for the diagnosis at delivery, these children require both dehydration and hydroelectrolytic disequilibrium correction; In the beginning they do not require potassium supplement, after four to six weeks lifetime they may benefit of it. Among the drugs used are the potassium-sparing diuretics such as spironolactone and indomethacin (1.5-2.5mg/kg/day) [18].

Bartter type 3, or Classic Bartter, is caused by CLCNKB gene mutations $[19,20]$. This gene is located at chromosomal region $1 p 36$ [5]; the chloride channel encoded by this gene is Bartter, age of onset in classical Bartter is about two years of age [3-5]; Symptoms include metabolic alkalosis, hypokalemia, normo or hipercalciuria, polyuria, which might manifest as enuresis; also polydipsia, vomit, constipation, salt craving, essential for urinary concentration mechanisms [3]. Different from neonatal failure to thrive, dehydration and fatigue, some of the patients may present with paresthesias, muscle weakness and transitory paralysis $[21,22]$; the hipercalciuria can produce nephrocalcinosis in some of the cases [23]; blood pressure can be normal or low [3]. Classical Bartter (type 3) is diagnosed by finding hypokalemia, hypochloremia and metabolic alkalosis; these patients may also present with hypomagnesaemia [24,25].

Type 4 Bartter is caused by BSDN gene mutations [5]. This gene encodes Barttin [15,26], and is located at $1 \mathrm{p} 31$ [4,27]. The Barttin protein acts as the $\beta$ sub-unit in the chloride channels (CLCKb) and it is required for proper insertion of CLC-k channels to the plasma membrane $[28,29]$. Mutant CLCKb interrupts the capability of potassium transport into the endolinfa, which leads to neurosensorial deafness. These patients are characterized by presenting with a more severe clinical picture than type 1 and 2 Bartter syndromes. Affected children are premature due to the severe polyhydramnios [28]; at delivery there is severe loss of salts requiring intravenous liquids. In addition, hypokalemia, hypocalcaemia, hypomagnesaemia, hipercalciuria, developmental delay and severe hypotonia are observed. Their facies are dysmorphic including triangular face, prominent forehead, large eye and protruding ears [4]; some of the patients may present with nephrocalcinosis and they often evolve to chronic renal failure [27]. They present poor response to the indomethacin $[5,27]$.

Type 5 Bartter is caused by CASR gene mutations. This gene encodes de $\mathrm{Ca} 2+$ receptor of the tubular cells from the ascending Henle loop. Its mutations segregate consistent with an autosomal dominant inheritance pattern; the encoded receptor localizes at the basolateral membrane of the ascending Henle thick loop $[4,20]$. The CaR mediates the effects of extracellular Ca++ on the Kidney and is an essential control point in the regulation of $\mathrm{Ca}++$ balance. It also seems to participate in the physiologic regulation of $\mathrm{NaCl}$ (sodium chloride) balance [20]. This Bartter subtype is characterized by hypocalcaemia, paratohormona insufficiency, hypokalemia, hypomagnesaemia and nephrocalcinosis [15].

The Gitelman syndrome is a different form of metabolic alkalosis with hypomagnesaemia and hypocalciuria [12,30]; It is associated to $S L C 12 A 3$ gene mutations (locus 16q13) (7). SLC12A3 encodes the co-transporter sodium chloride sensitive to thiazide diuretics [31]; the age of onset is, usually, at school age but it also can be diagnosed at adulthood [4]. It is less severe than Bartter syndrome since the urinary concentrating ability is conserved [32]; growth delay and polyuria are not observed; however, even though it is classified as a benign disorder, the combination of hypokalemia with hypomagnesaemia may cause the QTc prolongation triggering arrhythmias such as ventricular tachycardia, which may threat life $[18,33]$.

Gitelman's patients present with muscle weakness, fatigue, vertigo, polydipsia, nicturia, low blood presume and tetany crises [18,32]; some patients develop condrocalcinoses, possibly secondary to the chronic hypomagnesaemia. Other less frequent symptoms are lypotimia, polyuria, arthralgias, vomit, constipation, enuresis and periodic paralysis [32]. In Gitelman's syndrome it is observed a marked metabolic alkalosis (bicarbonate $>29 \mathrm{mEq} / \mathrm{L}$ ) with deep hypokalemia (potassium $<3 \mathrm{mEq} / \mathrm{L}$ ) hypomagnesaemia (magnesium $<0.5 \mathrm{mEq} / \mathrm{L}$ ) and hypocalciuria (urinary calcium $<2 \mathrm{mg} / \mathrm{kg} /$ day). These patients present with similar symptoms as Bartter disease, with exception of the hypomagnesaemia and hypocalciuria and that are capable of concentrating urine.

This is the first Colombian study aiming at characterize the phenotypic features in a set of patients with Bartter and Gitelman's syndromes. Here we report 18 cases in 14 families, most of them from Antioquia-Colombia.

\section{Patients and Methods}

This is a retrospective study based on reviewing the clinical records of patients with clinical diagnosis of Bartter or Gitelman's syndrome, who had been treated in 15 years. 18 patients were found in 14 non-related families. All but two families were from 
Antioquia, a department northwest in Colombia. The other two families were from Cordoba, Caribbean cost, who attended the child nephrology service in the Pontificia Universidad Bolivariana Clinic-Medellin.

Patients with other associated diseases were excluded, which could involve renal function such as hypertension, diabetes, and tubular renal acidosis, among others. Parents or tutors of the affected children filled out a form on perinatal history such as polyhydramnios, weight at delivery and gestational age; clinical symptoms before the diagnoses were recorded, such as fever, vomit, dehydration, polydipsia, paresthesias, breath paralysis, tetany, etc. In addition, we asked for family history, consanguinity evidence and other affected family members. The genealogy tree was drawn for each of the families involved in this study. After the treatment was started, hypokalemia and hypomagnesaemia were tested; also, rehospitalizations for this cause and current treatment were assessed.

In order to clarify the phenotype, the first laboratory tests at diagnosis were reviewed, which included artery gases, ionogram, renal ultrasound (looking for nephrocalcinosis) and renal function tests. Blood pressure was also measured and it was classified according to height and age.

The ethics committee of the Pontificia Bolivariana Clinic approved this study; patients and participating family members were explained the aims of the study and the forms of participating. All blood sample donors signed an informed consent.

\section{Results}

Eighteen patients corresponding to 14 unrelated families were analyzed. Of these patients $8(47 \%)$ presented with Gitelman's syndrome, $8(47 \%)$ presented neonatal Bartter and $2(11.1 \%)$ presented with classic Bartter. Current age ranged between 3-35 years; the average current age was 12.8 years. According to gender $8(45 \%)$ were males and $10(55 \%)$ were females.

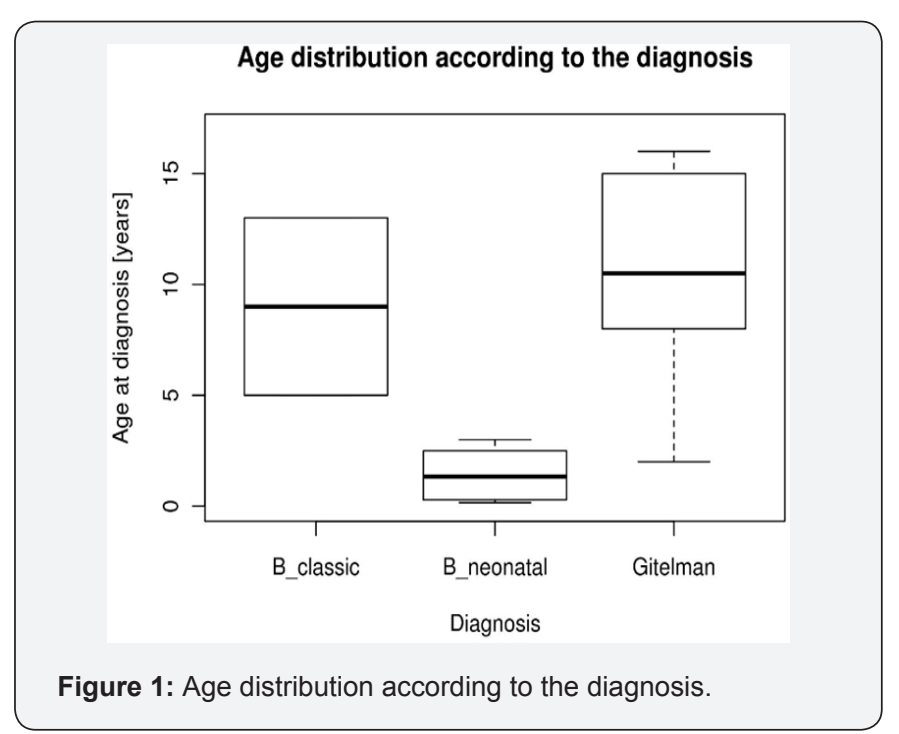

Regarding to the age at diagnosis, there were variable results. Thus, neonatal Bartter ranged between 2-36 months and a mean age of 18.43 months; average age for classic Bartter was 13 years; and Gitelman's range was 9 months to 16 years (average 6.38 years) (Figure 1).

The time elapsed from the beginning of the symptoms and the establishment of the diagnosis was as follows: Gitelman's syndrome ranged between 3-196 months; 5-120 months for classic Bartter; and between 1-36 months for neonatal Bartter (Figure 2).

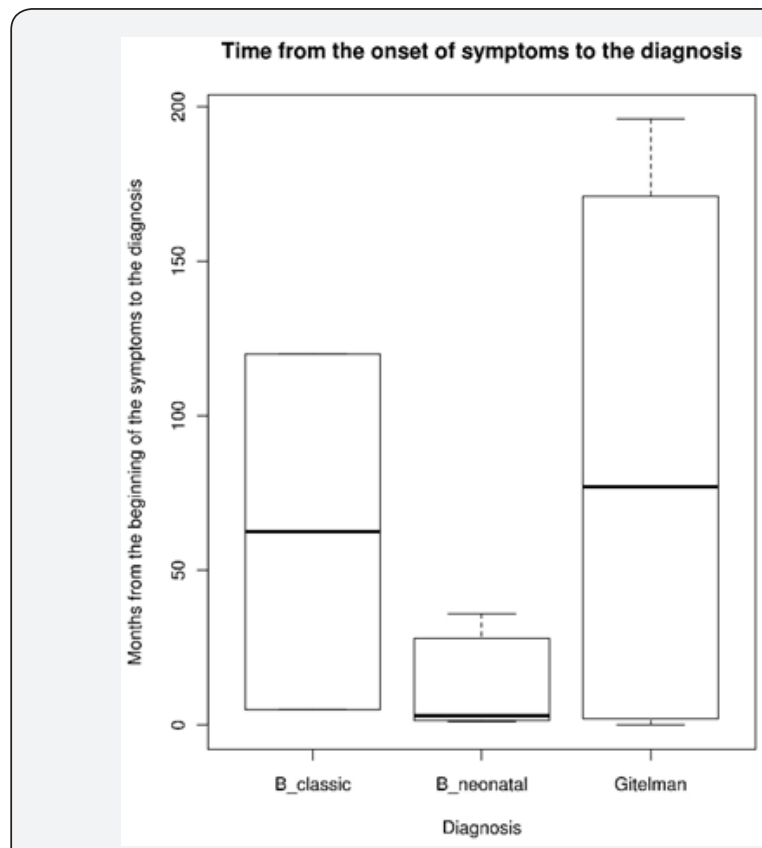

Figure 2: Time from the onset of symptoms of diagnosis.

Three out of 14 families presented demonstrated consanguinity. A fourth Family suspects sharing a common ancestor between the parents of the affected child. Three families presented two affected sibs. Regarding to perinatal history it was found that $87.5 \%$ of the patients with neonatal Bartter were born to early delivery (preterm) secondary to maternal polyhydramnios. The mean gestational age was 33.8 weeks to delivery.

Three patients (37.5\%) with Gitelman's syndrome presented early delivery (less than 37 weeks of gestational age). The patients with classic Bartter did not present these complications. Seven out of eight patients (87.5\%) with neonatal Bartter suffered hydroelectrolitic changes to birth, which was not observed in the remainder eleven patients.

Main symptoms in the patients with neonatal Bartter were vomit, polyuria, polydipsia, short stature, fever and paresthesias. Patients with Gitelman's syndrome mainly presented with muscle weakness, paresthesias, polyuria and polydipsia (Figure $3)$. Blood pressures in all of the patients were within normal limits. 


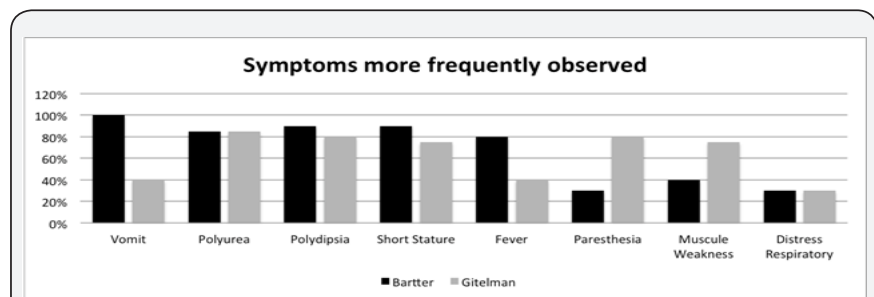

Figure 3: Symptoms more frequently observed.

Nephrocalcinosis was observed in six patients (35.2\%). Five of them were in the category of neonatal Bartter and one corresponded to Gitelman's syndrome. Regarding to the education level, it was found that qualitatively the patients with neonatal Bartter were behind related to children with the same age and without the disease. This was not observed in the other two categories of the disease (Classic Bartter or Gitelman's). Also, three patients with a diagnosis of neonatal Bartter presented with neurosensorial deafness; nonetheless, such deafness might be multi-factorial.

Among the laboratory tests performed for the diagnosis are arterial gases, ionogram, and both renal function and ultrasound. 87.5\% of the Patients with neonatal Bartter presented with metabolic alkalosis and hypokalemia. Renal function tests were normal. Patients with Gitelman's syndrome besides of alkalosis also presented with low blood magnesium levels. All of the patients presented their renal function was within the limits or normality (Table 1).

Table 1: Laboratory tests at diagnosis.

\begin{tabular}{|c|c|c|c|c|c|c|c|c|c|c|c|}
\hline Fam & Diagnosis & ID & PH blood & $\begin{array}{c}\mathrm{HCO} 3 \\
\mathrm{mmol} / \mathrm{L}\end{array}$ & $\mathrm{K} \mathrm{mmol} / \mathrm{l}$ & $\begin{array}{c}\mathrm{Cl} \\
\mathrm{mmol} / \mathrm{l}\end{array}$ & $\begin{array}{c}\mathrm{Ca} \\
\mathrm{mmol} / \mathrm{l}\end{array}$ & $\begin{array}{c}\mathrm{Na} \\
\mathrm{mmol} / \mathrm{l}\end{array}$ & $\underset{\mathrm{mmol} / \mathrm{L}}{\mathrm{Mg}}$ & $\begin{array}{c}\text { Creatinine } \\
\mathrm{mg} / \mathrm{dl}\end{array}$ & $\begin{array}{c}\text { Urine Ca } \\
\text { mg/dl }\end{array}$ \\
\hline 6 & $\begin{array}{l}\text { Classic } \\
\text { Bartter }\end{array}$ & 29 & 7.5 & 29 & 2 & 112 & 10 & 132 & 3 & 0.5 & NA \\
\hline 5 & $\begin{array}{l}\text { Classic } \\
\text { Bartter }\end{array}$ & 28 & 7.4 & 30.3 & 3 & 96 & 8.3 & 134 & 1.9 & 0.52 & 1.9 \\
\hline 13 & $\begin{array}{l}\text { Neonatal } \\
\text { Bartter }\end{array}$ & 72 & 7 & 36.42 & 2.7 & 87 & 8.4 & 136 & 2 & 0.5 & 10.8 \\
\hline 2 & $\begin{array}{l}\text { Neonatal } \\
\text { Bartter }\end{array}$ & 13 & 7.51 & 24 & 2.7 & 124 & 10.5 & 158 & 3 & 0.5 & \\
\hline 4 & $\begin{array}{l}\text { Neonatal } \\
\text { Bartter }\end{array}$ & 24 & 7.42 & $8 / 16 / 2010$ & 2.4 & 110 & 9.5 & 139 & 2.1 & 0.41 & 0.2 \\
\hline 4 & $\begin{array}{c}\text { Neonatal } \\
\text { Bartter }\end{array}$ & 23 & 7.49 & $4 / 19 / 2010$ & 3.2 & 100 & $1 / 9 / 2010$ & 132 & 2.7 & 0.68 & NA \\
\hline 7 & $\begin{array}{c}\text { Neonatal } \\
\text { Bartter }\end{array}$ & 31 & 7.5 & 22.2 & 2.3 & 101 & 11 & 143 & 2.2 & 0.4 & NA \\
\hline 9 & $\begin{array}{c}\text { Neonatal } \\
\text { Bartter }\end{array}$ & 40 & 7.51 & 46.9 & 0.99 & 75 & 8.5 & 132 & 1.6 & 0.4 & NA \\
\hline 10 & $\begin{array}{c}\text { Neonatal } \\
\text { Bartter }\end{array}$ & 42 & 7.53 & 23 & 3 & 10 & 9 & 135 & 1.9 & 0.6 & 7.6 \\
\hline 3 & $\begin{array}{c}\text { Neonatal } \\
\text { Bartter }\end{array}$ & 19 & 7.49 & $1 / 25 / 2010$ & $6 / 2 / 2010$ & & 10.5 & 149 & 3.5 & 0.8 & $9 / 7 / 2010$ \\
\hline 8 & Gitelman & 36 & $7 / 1 / 1949$ & 29 & 2.5 & 106 & 1.16 & 140 & 1.6 & 0.6 & 6.87 \\
\hline 14 & Gitelman & 65 & 7.58 & 29 & 1.5 & 85 & 8.4 & 135 & 1 & 0.3 & 7.7 \\
\hline 14 & Gitelman & 66 & 7.56 & 28.4 & 2.8 & 87 & 11.7 & 131 & 1.7 & 0.39 & 7.9 \\
\hline 1 & Gitelman & 3 & 7.5 & $9 / 26 / 2010$ & 2.41 & 112 & 10 & 150 & $3 / 1 / 2010$ & 0.5 & $4 / 11 / 2010$ \\
\hline 1 & Gitelman & 4 & 7.48 & 25 & $5 / 2 / 2010$ & 115 & 11 & 155 & 2 & 0.8 & NA \\
\hline 11 & Gitelman & 49 & NA & NA & 3 & 99 & 10.2 & 145 & 1.38 & 0.5 & NA \\
\hline 11 & Gitelman & 50 & NA & NA & 2.9 & 101 & 10 & 145 & 1.3 & 0.7 & NA \\
\hline 12 & Gitelman & 53 & 7.49 & 25.4 & 2.5 & 101 & 9.7 & 138 & 1.2 & 0.8 & NA \\
\hline
\end{tabular}


Regarding to the treatment, it was found that $100 \%$ of the patients with the neonatal Bartter syndrome are being treated with potassium supplements; $87.5 \%$ are being treated with spironolactone; $62.5 \%$ take indomethacin; $37.5 \%$ are treated with angiotensin-converting enzyme inhibitors and only one of the patients takes magnesium.

One hundred per cent of the patients Gitelman's syndrome required potassium and magnesium; $25 \%$ indomethacin; $62.5 \%$ spironolactone. And only one patient received ECA inhibitors.

\section{Discussion}

This study describes the clinical and laboratory characteristics of a set of patients with Bartter or Gitelman's syndromes; all these patients attended the child nephrology consult at Bolivariana Clinic. In total, 18 patients (clustered in 14 families) were evaluated. All parents were non symptomatic and in $38 \%$ of the families there was evidence of consanguinity, which reinforces the idea of autosomal recessive inheritance, described previously [34].

Even though the prevalence of this disease has not yet been established in Colombia, its incidence seems to be relatively high. It may be explained considering that in Antioquia, North West Colombia, there are previous reports of founder effects and high levels of isonimy, which suggests high levels of consanguinity [35].

Regarding to the socio-demographic findings, there was not predominance of a gender. The age at diagnosis was similar to that reported in the literature [34]. Thus, patients with neonatal Bartter were diagnosed early since their symptoms appear even from the prenatal period and in a more aggressively manner. On the other hand, patients with Gitelman's syndrome are characterized by prolonged symptom-free intervals with bizarre symptoms; this is in agreement with its diagnosis even years later from the beginning of the symptoms.

Regarding to the clinic and laboratory findings, the patients described here present phenotypic characteristics as reported previously. Thus patients with classic Bartter syndrome started their symptoms at infancy, with hypercalciuria and nephrocalcinosis [36]. For the contrary, patients with Gitelman's syndrome were diagnosed at school age or early adulthood by presenting tetany crisis, cramps and hypomagnesaemia signs [6]. Of the patients with neonatal Bartter, $87.5 \%$ were prematurely born, complicated with maternal polyhidramnius. After childbirth, frequent episodes of vomit, dehydration and short stature were found.

In some situations it is difficult to differentiate from classic Bartter and Gitelman's syndrome. It happened in patients that initially were diagnosed as having Bartter syndrome, but then due to low magnesium levels the diagnosis was switched to Gitelman's.
In the other hand, it was found a great interfamilial phenotypic variability. Patients 23 and 24 from family 4 were diagnosed initially as having renal tubular acidosis (Table 1); then, according to further laboratory exams the diagnosis was changed to neonatal Bartter syndrome. Nonetheless, in one of the sibs the symptoms were much more aggressive (subject. 23 , Table 1) than in the other, who albeit presented laboratory findings compatible with Bartter syndrome, his symptoms are just mild (subject. 24, Table 1).

Phenotypic variation has previously been reported in a family with the R438H CLCNKB gene mutation [37]. Some individuals in this family carrying the mutation presented clinical manifestations compatible with Bartter, while other individuals in the same family manifested symptoms compatible with Gitelman's syndrome. This phenotypic variability may be explained by some physiologic factors that may contribute to a wide range of phenotypes. For instance, it has been suggested the presence of other chloride channels that may develop a greater conductance or greater number and this could increase the reabsorption of chloride at renal level [37].

Another, yet interesting study, reported the presence of both Gitelman's and Bartter syndromes in two sisters. One of them presented with hypokalemia, hypomagnesaemia and hypocalciuria while the other sister presented low levels of serum magnesium and normal levels of calcium. This family currently is lacking a genetic study $[37,38]$.

In our patients, nephrocalcinosis was predominant in the patients with neonatal Bartter (62.5\%). In Gitelman's it was present in $12.5 \%$ of the cases. This contrast may be explained by the hipercalciuria in Bartter, contrary to the observed in patients with Gitelman's.

All of the patients, disregarding their age, continue to receive supplements of potassium and other medicines such as indomethacin, spironolactone and angiotensin-converting enzyme inhibitors. This requirement points that this pathology is not a renal maturation disorder, but a genetic defect that is not corrected by time.

Disregarding of the severity of the symptoms, none of the patients presented with renal failure. It is consistent with the low incidence of this comorbidity in these syndromes. A set of 20 patients with Bartter syndrome, from Costa Rica presented only one patient with renal insufficiency. Moreover, although long term use of indomethacin has been associated with diminished renal function [34], 38.8\% (7/18) of the patients reported here received it even until present and none of them demonstrated renal function alteration due to this drug. This observation is in agreement with other reports where it is indicated that prostaglandin inhibitors in these cases do not cause deterioration of the renal function after 10-15 years of treatment [39]. 


\section{References}

1. Das S (1994) Early history of venogenic impotence. Int J Impot Res 6(4): 183-189.

2. Virag R (2002) Intracavernous injection of papaverine for erectile failure. 1982. J Urol 167(2): 1196.

3. Sohn M, Hatzinger M, Goldstein I, Krishnamurti S (2013) Standard operating procedures for vascular surgery in erectile dysfunction revascularization and venous procedures. J Sex Med 10(1): 172-179.

4. Bari V, Ahmed MN, Rafique MZ, Ashraf K, Memon WA, et al. (2006) Evaluation of erectile dysfunction with color Doppler sonography. J Pak Med Assoc 56(6): 258-261.

5. Kawanishi Y, Lee KS, Kimura K, Kojima K, Yamamoto A, et al. (2001) Feasibility of multi-slice computed tomography in the diagnosis of arteriogenic erectile dysfunction. BJU Int 88(4): 390-395.

6. Kurbatov DG, Kuznetsky YY, Kitaev SV, Brusensky VA (2008) Magnetic resonance imaging as a potential tool for objective visualization of venous leakage in patients with veno-occlusive erectile dysfunction. Int J Impot Res 20(2): 192-198.

7. Virag R, Paul JF (2011) New classification of anomalous venous drainage using caverno-computed tomography in men with erectile dysfunction. J Sex Med 8(5): 1439-1444.

8. Chen SC, Hsieh CH, Hsu GL, Wang CJ, Wen HS, et al. (2005) The progression of the penile vein: could it be recurrent? J Androl 26(1): 53-60.
9. Wespes E, Wildschutz T, Roumeguere T, Schulman CC (2003) The place of surgery for vascular impotence in the third millennium. J Urol $170(4$ Pt 1): 1284-1286.

10. Popken G, Katzenwadel A, Wetterauer U (1999) Long-term results of dorsal penile vein ligation for symptomatic treatment of erectile dysfunction. Andrologia 31 (Suppl 1): 77-82.

11. Lewis RW, Puyau FA, Bell DP (1986) Another surgical approach for vasculogenic impotence. J Urol 136(6): 1210-1212.

12. Herwig R, Bayerl M (2015) Superficial tunica albuginea rupture as initial starting point of Peyronie's disease: a topic for interdisciplinary consideration. Biomed Res Int 2015: 751372.

13. Izumi K, Kawanishi Y, Muguruma H, Kusuhara Y, Komori M, et al. (2011) Virtual cavernoscopy: a novel diagnostic tool for use in the corpus cavernosal lumen in patients with erectile dysfunction. BJU Int 108(8): 1316-1320.

14. Herwig R, Sansalone S (2015) Venous leakage treatment revisited: pelvic venoablation using aethoxysclerol under air block technique and Valsalva maneuver. Arch Ital Urol Androl 87(1): 1-4.

15. Kawanishi Y, Izumi K, Muguruma H, Mashima T, Komori M, et al. (2011) Three-dimensional CT cavernosography: reconsidering venous ligation surgery on the basis of the modern technology. BJU Int 107(9): 1442-1446.

\section{Your next submission with Juniper Publishers} will reach you the below assets

- Quality Editorial service

- Swift Peer Review

- Reprints availability

- E-prints Service

- Manuscript Podcast for convenient understanding

- Global attainment for your research

- Manuscript accessibility in different formats

( Pdf, E-pub, Full Text, Audio)

- Unceasing customer service

Track the below URL for one-step submission https://juniperpublishers.com/online-submission.php 